patients with chronic manifestations of filarial lymphoedema in an area endemic for lymphatic filariasis. Theses in Community Medicine, Post Graduate Institute of Medicine, University of Colombo, 2009.

15. Fostein MF, Folstein SE, McHugh PR. "Mini-mental state”. A practical method for grading the cognitive state of patients for the clinician. Journal of Psychiatric Research 1975; 12: 189-98.

16. de Silva HA, Gunatilake SB. Mini mental status examination in Sinhalese: a sensitive test to screen for dementia in Sri Lanka. International Journal of Geriatric Psychiatry 2002; 17: 134-9.

17. Podsiadlo D, Richardson S. The timed "Up and Go": a test of basic functional mobility for frail elderly persons. Journal of the American Geriatrics Society 1991; 39: 142-8.

18. Munasinghe L. Prevalence and correlates of physical abuse within marriage in a cohort of pregnant women. Theses in
Community Medicine, Post Graduate Institute of Medicine, University of Colombo, 2002.

19. Minnesota Falls Prevention Checklist; Check your housePrevent falls. Minnesota Safety Council, 2009 [cited 2009 June 18] Available from: http://www.mnsafetycouncil.org/ seniorsafe/falls/index.cfm?SO=1

20. Hand Book for Elderly. Sri Lanka: Department of Social Services, 2001.

21. What are the main risk factors for falls amongst older people and what are the most effective interventions to prevent these falls? Health Evidence Network, World Health Organization, 2004.

22. Hennekens $\mathrm{CH}$, Buring JE. Epidemiology in Medicine, 2nd ed. Boston/Toronto: Little Brown and company, 1987.

23. Silviaa D, Ersiliaa L, Francescaa L, et al. Risk Factors for Falls in Community-dwelling Older People: A Systematic Review and Meta-analysis. Epidemiology 2010; 21: 658-68.

\title{
Prevalence of enterobiasis among primary school children in Ragama, Sri Lanka
}

\author{
N K Gunawardena, T N Chandrasena, N R de Silva
}

(Index words: Enterobius vermicularis, prevalence, school children, Sri Lanka, helminth)

\begin{abstract}
Objectives To determine the prevalence of enterobiasis among school children in Ragama Medical Officer of Health $(\mathrm{MOH})$ region and the association between clinical features, potential risk factors and infection status.

Design Cross sectional study.

Setting School based.

Participants 260 school children aged 5-7 years, attending five state schools in the Ragama $\mathrm{MOH}$ region.

Main outcome measures Prevalence of Enterobius vermicularis infection as diagnosed using adhesive cellophane tapes on the perianal skin on 2 consecutive days.

Results The overall prevalence of enterobiasis was 38\%. The risk factors significant on a univariate analysis were male gender, maternal under-education, non-permanency of paternal employment, more household members, more siblings in a family, more persons sleeping with an index child and lack of recent
\end{abstract}

deworming. On a multivariate model more household members, more children in a household, more persons sleeping with the index child, non-permanency of paternal employment and lack of recent deworming were significantly associated with infection. None of the clinical manifestations evaluated (peri-anal itching, insomnia, abdominal pain, and enuresis) showed a significant association with enterobiasis.

Conclusions Enterobiasis is highly prevalent among primary school children in Ragama.

Ceylon Medical Journal 2013; 58: 106-110

\section{Introduction}

Enterobiasis, considered one of the commonest childhood intestinal nematode infections, has a worldwide distribution. The important routes of transmission are 
through oral and respiratory tracts. Oral infection may occur through the anus-hand-mouth route, onycophagia and via objects or food contaminated with Enterobius vermicularis eggs. Inhalation of dust contaminated with parasite eggs constitutes respiratory infection [1]. Due to its contagious nature, enterobiasis tends to occur more among large families and institutions such as schools, hostels and asylums especially with crowded conditions [1]. Although highly prevalent, this infection is often overlooked as most infections remain asymptomatic or cause only mild disturbances such as pruritus ani, insomnia, restlessness, irritability and nocturnal enuresis. However, serious morbidity such as appendicitis, eosinophilic enterocolitis and pelvic inflammatory disease have been reported as consequences of enterobiasis [2-4]. Furthermore an adverse impact on school performance has been suggested [5].

Diagnosis of enterobiasis is mainly based on detection of the characteristic eggs in the perianal region using swabs or adhesive tapes. Alternatively, ova may be seen in faeces or scrapings from under finger nails and adult worms may be detected in the perianal skin at night. Faecal examination in suspected cases is of limited value as eggs are present in the faeces of only $5-15 \%$ of infected persons [1]. Swabbing needs to be done at night to coincide with oviposition, or first thing in the morning prior to washing or cleaning the perianal region.

Although enterobiasis is frequently clinically encountered in Sri Lanka and is a known problem among primary school children elsewhere, just one reported study (conducted in the 1980s) has examined the true extent of the problem [6], whereas the epidemiology of the other intestinal nematode infections in Sri Lanka has been widely studied [7-10]. The low morbidity associated with enterobiasis and the need for perianal swabbing (more cumbersome than faecal examination) are probable reasons for this deficiency.

The present survey conducted in the Ragama Medical Officer of Health ( $\mathrm{MOH}$ ) region, was a preliminary study undertaken to investigate the prevalence, to evaluate the association of clinical manifestations and potential risk factors of disease with infection.

\section{Methods}

Permission was obtained from the relevant zonal education offices and approval for the study was obtained from the Ethics Review Committee, Faculty of Medicine, University of Kelaniya. A cross sectional descriptive study was performed among children in Years (Grades) one and two of seven randomly selected, state run schools in the Ragama MOH area. Ragama is a semi-urban town with a population of about 34000 , situated $13 \mathrm{Km}$ north of the capital city, Colombo. The children attending the staterun schools of the area were predominantly from lowermiddle class families. Of the seven schools selected, two had very few students registered in the respective grades and thus were excluded from analysis. A total of 302 students were recruited.

Diagnosis of infection was based on examination of peri-anal swabs obtained on two consecutive days using adhesive cellophane tapes (HYPONex Japan Co. Ltd., Japan). The peri-anal swabs were distributed among the mothers or principal care takers after demonstrating the correct procedure of using them on a dummy. The returned swabs were examined microscopically by a skilled technical officer in the Department of Parasitology, Faculty of Medicine, University of Kelaniya. Infection was defined as the presence of $E$. vermicularis eggs in peri-anal swabs of one or both of two consecutive days.

A pre-tested self-administered questionnaire completed by the mother or principal care-taker was used to evaluate clinical manifestations and risk factors associated with enterobiasis. The information collected included anthelmintic medication, finger nail-biting, handwashing behavior, frequency of bathing, changing bed linen, and finger nail-trimming, number of household occupants, number and characteristics of people sharing the bedroom with the student, parental education and employment. Clinical features evaluated were peri-anal itching, insomnia, nocturnal enuresis, abdominal pain and loss of appetite. On return of the swabs and completed questionnaires, the mothers or principal care takers were educated on transmission and prevention of enterobiasis through leaflets. The parents or care-givers of the children were informed of the results of the microscopic examination of swabs and all infected children together with their classmates were offered anthelmintic treatment.

The data were cleaned and transported to Stata 12.1 for statistical analysis (Stata Corp, 2012). Explanatory variables (except age of the child) significant at $p<0.2$ level in univariate analysis were included in the model, which looked for associations significant at $p<0.05$.

\section{Results}

In June and July 2011, a total of 302 children from five schools were recruited for the survey. Of those recruited, 260 complied with the given instructions and returned the swabs and completed questionnaires (rate of compliance $86.1 \%$ ). Mean age of the population was 6 years (range $5-7$ ) with $50.4 \%$ males. Ninety nine were found to be positive for enterobiasis with an overall prevalence of $38.1 \%$ when examined on two consecutive days. The prevalence derived by a single peri-anal swab examination was $20 \%$. This disparity highlights the importance of repeated swabbing for increased sensitivity [11].The rate of infection among schools varied from $30-51.5 \%$ (Table 1). Boys had a significantly higher rate of infection than girls (58.6\% Vs 41.4\%; $p=0.038)$. About one fifth of the study population (21.8\%) had been de-wormed within 30 days of the survey. 
Table 1. Enterobius vermicularis infection by school

\begin{tabular}{lccc}
\hline Schools surveyed & $\begin{array}{c}\text { Number } \\
\text { examined }\end{array}$ & $\begin{array}{c}\text { Number } \\
\text { positive }\end{array}$ & $\begin{array}{c}\text { Prevalence } \\
\text { rate \% }\end{array}$ \\
\hline School 1 & 23 & 11 & 47.8 \\
School 2 & 60 & 18 & 30.0 \\
School 3 & 92 & 36 & 39.1 \\
School 4 & 33 & 17 & 51.5 \\
School 5 & 52 & 17 & 32.7 \\
Total & 260 & 99 & 38.0 \\
\hline
\end{tabular}

Risk factors were studied in relation to enterobiasis. Explanatory variables that were significantly associated with infection on univariate analysis included male sex, maternal under-education, non-permanency of paternal employment, more members in household, more siblings in a family and more persons sleeping with an index child. Recent de-worming had a protective effect on infection. After adjustment in the multivariable model (see table 2 for variables included in the model), more children in a household, overcrowded household conditions, crowded sleeping environment of an index child, non-permanency of paternal employment and absence of recent de-worming remained significantly associated with enterobiasis. None of the clinical manifestations evaluated (peri-anal itching, insomnia, abdominal pain, and enuresis) were significantly associated with enterobiasis. None of the personal hygiene measures (washing hands before meals, frequent trimming of finger-nails, bathing and changing bed linen) and risk behaviours (nail-biting and thumb-sucking) investigated, appeared to have a significant impact on enterobiasis.

\section{Discussion}

In most countries, E.vermicularis is considered to be the most commonly encountered intestinal nematode of humans [12]. Even in the affluent United States, it is reported as the most prevalent nematode [13]. This could be attributed to the relative ease of transmission causing frequent re-infections and the failure to clear parasites due to incomplete medication. The results of this preliminary survey indicate that over one third of primary school children of the Ragama $\mathrm{MOH}$ area were infected with E. vermicularis. Similar high rates of infection have been reported in Malaysia (40.4\%) and Argentina (41.42\%) $[14,15]$.

Surveys that specifically focus on enterobiasis (diagnosed by peri-anal swabs) are mostly from countries with an established screening/medication program and thus the rates of infection are comparatively low. In such countries a significant reduction in prevalence is obvious when comparing results of surveys done before and after year 2000. In Turkey, the overall rate of enterobiasis of $45.9 \%$ observed in the period 1985-2000, decreased to $16 \%$ in the period 2000-2008 years [5]. Similar declines in prevalence have been observed in countries such as Greece (22.1\% to 5.2\%) and Korea (17.1\% to 7.9\%) [16-18].

The only past study on enterobiasis in Sri Lanka was done over two decades ago. It describes a prevalence of 33.3\% among paediatric hospital admissions at the Peradeniya Teaching Hospital using a single peri-anal swab examination [6]. Because this rate is based on only a single swab, it is likely that it is an underestimate of the true prevalence.

In agreement with the present findings a significant association between enterobiasis and maternal under education has been previously reported [19-21]. The association between larger families and enterobiasis has also been previously observed in a survey of preschool children in Turkey where the higher risk was attributed to the presence of school going elder siblings [21]. In contrast to the present survey, poor personal hygiene such as not washing hands before meals, nail biting and thumb sucking (behaviours that would promote ingestion of worm eggs in environment) were identified as significant risk factors for enterobiasis in Taiwan and Korea [22, 23]. However other surveys, including the present, have failed to show this association [21]. This disparity could be partly attributed to the tendency to hide deficiencies in hygiene in order to avoid embarrassment or due to the respiratory route of infection playing a dominant role in the process of transmission. Paternal employment in a permanent job was also associated with reduced risk of infection. This was probably an indicator of better economic status and living conditions.

The importance of anthelmintics, whether correctly administered or not (group therapy and repeated medication) in the control of enterobiasis was shown in surveys in the past as well as present [23]. Since anthelmintics are not effective against eggs and larval stages of E. vermicularis, infections acquired 1-2 weeks prior to medication will not be cured by one time medication; hence the need for a second medication two weeks following the first. The importance of group medication was shown in a survey of kindergartens in the Busan Metropolitan city, Republic of Korea, where out of 21 kindergartens, the one which practiced group medication (all the children and teachers were de-wormed at the same time every six months, including repeat medication) was shown to be free of infection whereas the rest had a higher-than-average rate of enterobiasis [23]. Similarly the efficacy of group medication has been further established [24].

Sri Lanka has no national de-worming programs for enterobiasis, and in the present survey only a quarter of those recently de-wormed $(19 / 72=26.3 \%)$ had a repeat 
Table 2. Risk factors associated with enterobiasis

\begin{tabular}{|c|c|c|c|c|c|c|}
\hline & \multirow[b]{3}{*}{ Number } & \multirow[b]{3}{*}{$\%$ infected } & \multicolumn{4}{|c|}{ Enterobius vermicularis infection } \\
\hline & & & \multicolumn{2}{|c|}{ Univariate } & \multicolumn{2}{|c|}{ Multivariate } \\
\hline & & & OR $(95 \% C I)$ & $\begin{array}{c}\text { Sample } \\
P\end{array}$ & $\begin{array}{c}\text { Adjusted OR } \\
(95 \% \text { CI })\end{array}$ & $\begin{array}{c}\text { Sample } \\
P\end{array}$ \\
\hline \multicolumn{7}{|l|}{ Sex } \\
\hline Male & 131 & 44.3 & 1.0 & & 1.0 & \\
\hline Female & 129 & 31.8 & $0.6(0.4-0.9)$ & 0.039 & $0.6(0.3-1.0)$ & 0.059 \\
\hline \multicolumn{7}{|l|}{ Age } \\
\hline 5 yrs & 16 & 25.0 & 1.0 & & 1.0 & \\
\hline 6 yrs & 223 & 39.0 & $1.9(0.6-6.1)$ & 0.272 & $3.2(0.9-11.5)$ & 0.068 \\
\hline 7 yrs & 21 & 38.1 & $1.8(0.4-7.7)$ & 0.402 & $2.5(0.5-12.2)$ & 0.263 \\
\hline \multicolumn{7}{|l|}{ No. of household members } \\
\hline 3 members or less & 32 & 25.0 & 1.0 & & 1.0 & \\
\hline 4 members & 82 & 37.8 & $1.8(0.7-4.5)$ & 0.199 & $3.3(1.2-8.8)$ & 0.017 \\
\hline 5 members & 85 & 42.4 & $2.2(0.8-5.4)$ & 0.088 & $3.7(1.4-9.6)$ & 0.008 \\
\hline 6 or more & 32 & 41.1 & $2.1(0.8-5.4)$ & 0.133 & $4.8(1.8-13.0)$ & 0.002 \\
\hline \multicolumn{7}{|c|}{ No of children in household } \\
\hline One child or no child & 95 & 31.6 & 1.0 & & 1.0 & \\
\hline Two children & 118 & 39.8 & $1.4(0.8-2.5)$ & 0.214 & $1.2(0.6-2.3)$ & 0.551 \\
\hline Three or more children & 37 & 56.8 & $2.8(1.3-6.2)$ & 0.009 & $2.9(1.1-7.7)$ & 0.025 \\
\hline \multicolumn{7}{|c|}{ Nos. sleep with index child } \\
\hline One member & 41 & 17.1 & 1.0 & & 1.0 & \\
\hline Two members & 67 & 40.3 & $3.3(1.2-8.4)$ & 0.014 & $3.5(1.3-9.5)$ & 0.014 \\
\hline Three members & 77 & 41.6 & $3.5(1.4-8.8)$ & 0.009 & $3.4(1.3-9.0)$ & 0.013 \\
\hline Four members & 66 & 48.5 & $4.5(1.7-11.8)$ & 0.002 & $3.4(1.2-9.6)$ & 0.019 \\
\hline \multicolumn{7}{|l|}{ Treatment within 30 days } \\
\hline No & 85 & 42.3 & 1.0 & & 1.0 & \\
\hline Yes & 13 & 23.2 & $0.4(0.2-0.8)$ & 0.011 & $0.4(0.2-0.9)$ & 0.019 \\
\hline \multicolumn{7}{|l|}{ Paternal employment } \\
\hline Un-employed/casual & 132 & 47.0 & 1.0 & & 1.0 & \\
\hline Permanent & 122 & 29.5 & $0.5(0.3-0.8)$ & 0.005 & $0.4(0.2-0.7)$ & 0.001 \\
\hline \multicolumn{7}{|l|}{ Paternal education $^{a}$} \\
\hline Schooling up to year 5 & 12 & 41.7 & 1.0 & & & \\
\hline Passed year 8 & 56 & 44.6 & $1.1(0.3-4.0)$ & 0.851 & & \\
\hline Passed O/L & 134 & 38.1 & $0.9(0.3-2.9)$ & 0.806 & & \\
\hline Passed A/L & 55 & 32.7 & $0.7(0.2-2.4)$ & 0.556 & & \\
\hline \multicolumn{7}{|l|}{ Maternal employment ${ }^{\mathrm{a}}$} \\
\hline Un-employed/casual & 203 & 38.9 & 1.0 & & & \\
\hline Permanent & 43 & 34.9 & $0.8(0.4-1.7)$ & 0.621 & & \\
\hline \multicolumn{7}{|l|}{ Maternal education ${ }^{a}$} \\
\hline Schooling up to year 5 & 18 & 50.0 & 1.0 & & & \\
\hline Passed year 8 & 48 & 47.9 & $0.9(0.3-2.7)$ & 0.888 & & \\
\hline Passed $\mathrm{O} / \mathrm{L}$ & 140 & 38.6 & $0.6(0.2-1.6)$ & 0.350 & & \\
\hline Passed A/L & 51 & 23.5 & $0.3(0.1-0.9)$ & 0.041 & & \\
\hline
\end{tabular}

$\mathrm{OR}=$ odds ratio, $95 \% \mathrm{CI}=95 \%$ confidence interval, $\mathrm{P}=p$ value, $1.0=$ reference group

${ }^{\text {a }}$ variables not used for final model 
medication. This implies the need to educate the health personnel as well as the care-takers regarding correct treatment of enterobiasis. These factors may provide a clue as to why the prevalence of enterobiasis remains high. In most parts of Sri Lanka the prevalence of other intestinal helminth infections among school children has declined owing to regular de-worming and improvements in living and sanitary conditions [7, 9, 10]. Therefore enterobiasis is now the most prevalent nematode infection in the paediatric age group in Ragama MOH area.

In conclusion, results of this survey indicate that enterobiasis is highly prevalent among the primary school children in Ragama. Wider studies are required to establish the extent of the infection in other parts of the country. Specific control measures are required to interrupt the transmission cycle of E. vermicularis. Improvements in living standards and enhancement of female literacy would further ensure the success of control efforts.

\section{Acknowledgements}

Prof. E Kimura of Aichi Medical University for his kind supply of cellophane tapes, Drs B P Senarathne and GMKS Silva for data collection and Mr. Waruna Nilaweera of the Department of Parasitology, Faculty of Medicine, University of Kelaniya for technical assistance.

\section{References}

1. Brooker S, Bundy DAP. Enterobiasis. In: Cook GC, Zumla IA, eds. Manson's Tropical Diseases. 22nd ed. Saunders, 2009: 1515-7.

2. Sah SP, Bhadani PP. Enterobius vermicularis causing symptoms of appendicitis in Nepal. Tropical Doctor 2006; 36: $160-2$.

3. Tandan T, Pollard AJ, Money DM, Scheifele DW. Pelvic inflammatory disease associated with Enterobius vermicularis. Archives of Disease in Childhood 2002; 86: 439-40.

4. Macedo T, MacCarty RL. Eosinophilic ileocolitis secondary to Enterobius vermicularis: case report. Abdominal Imaging 2000; 25: 530-2.

5. Degerli S, Malatyali E, Ozcelik S, Celiksoz A. Enterobiosis in Sivas, Turkey from past to present, effects on primary school children and potential risk factors. Turkiye Parazitolojii Dergisi 2009; 33: 95-100.

6. Wanigasooriya I, Wijesundera MdS. Pinworm (Enterobius vermicularis) infestation in paediatric hospital admissions. Annual Sessions of the Kandy Society of Medicine Kandy 1985; 26-7.

7. Pathmeswaran A, Jayatissa R, Samarasinghe S, et al. Health status of primary schoolchildren in Sri Lanka. Ceylon Medical Journal 2005; 50: 46-50.

8. Gunawardena NK, Amarasekera ND, Pathmeswaran A, de Silva NR. Effect of repeated mass chemotherapy for filariasis control on soil-transmitted helminth infections in Sri Lanka. Ceylon Medical Journal 2008; 53: 13-6.
9. Gunawardena K, Kumarendran B, Ebenezer R, et al. Soiltransmitted helminth infections among plantation sector schoolchildren in Sri Lanka: prevalence after ten years of preventive chemotherapy. PLoS Neglected Tropical Diseases 2011; 5: e1341.

10. de Silva NR, Pathmeswaran A, Fernando SD, et al. Impact of mass chemotherapy for the control of filariasis on geohelminth infections in Sri Lanka. Annals of Tropical Medicine and Parasitology 2003; 97: 421-5.

11. Remm M, Remm K. Effectiveness of repeated examination to diagnose enterobiasis in nursery school groups. The Korean Journal of Parasitology 2009; 47: 235-41.

12. Neva FA, Brown HW. Basic Clinical Parasitology. 6th ed: Appleton and Lange; 1994.

13. Kucik CJ, Martin GL, Sortor BV. Common intestinal parasites. American Family Physician 2004; 69: 1161-8.

14. Norhayati M, Hayati MI, Oothuman P, et al. Enterobius vermicularis infection among children aged 1-8 years in a rural area in Malaysia. The Southeast Asian Journal of Tropical Medicine and Public Health 1994; 25: 494-7.

15. Pezzani BC, Minvielle MC, de Luca MM, et al. Enterobius vermicularis infection among population of General Mansilla, Argentina. World Journal of Gastroenterology 2004; 10: 2535-9.

16. Platsouka E, Stephansou T, Marselou-Kinti O. Frequency of Enterobius vermicularis in children from the area of central Greece. Deltion Hellinikis Microbiol Eterial 1985; 30: 51-9.

17. Yang YS, Kim SW, Jung SH, et al. Chemotherapeutic trial to control enterobiasis in schoolchildren. Korean Journal of Parasitology 1997; 35: 265-9.

18. Kang S, Jeon HK, Eom KS, Park JK. Egg positive rate of Enterobius vermicularis among preschool children in Cheongju, Chungcheongbuk-do, Korea. Korean Journal of Parasitology 2006; 44: 247-9.

19. Okyay P, Ertug S, Gultekin B, et al. Intestinal parasites prevalence and related factors in school children, a western city sample - Turkey. BMC Public Health 2004; 4: 64.

20. Quihui L, Valencia ME, Crompton DW, et al. Role of the employment status and education of mothers in the prevalence of intestinal parasitic infections in Mexican rural schoolchildren. BMC Public Health 2006; 6: 225.

21. Muge OA, Baykan Z, Artan C. Enterobiasis among preschool children: a study from Kayseri, Turkey. Japanese Journal of Infectious Diseases 2008; 61: 482-3.

22. Sung JF, Lin RS, Huang KC, et al. Pinworm control and risk factors of pinworm infection among primary-school children in Taiwan. The American Journal of Tropical Medicine and Hygiene 2001; 65: 558-62.

23. Kim DH, Son HM, Kim JY, et al. Parents’ knowledge about enterobiasis might be one of the most important risk factors for enterobiasis in children. Korean Journal of Parasitology 2010; 48: 121-6.

24. Kang IS, Kim DH, An HG, et al. Impact of health education on the prevalence of enterobiasis in Korean preschool students. Acta Tropica 2012; 122: 59-63. 